\title{
PROTOTIPE ROBOT PENGANTAR MAKANAN BERBASIS ARDUINO MEGA DENGAN INTERFACE WEB BROWSER
}

\author{
Asep Saefullah ${ }^{1}$ \\ Endang Sunandar ${ }^{2}$ \\ Muhammad Nur Rifai ${ }^{3}$ \\ Dosen Jurusan Sistem Komputer STMIK Raharja ${ }^{1}$, Dosen Jurusan Sistem Komputer STMIK \\ Raharja $^{2}$, Alumni STMIK Raharja Jurusan Sistem Komputer ${ }^{3}$ \\ e-mail: asep.saefullah@raharja.info, endang.sunandar@raharja.info,nurrifai@raharja.info
}

Diterima: 6 Juni 2017/ Disetujui : 13 Juni 2017

\begin{abstract}
In general, the process of delivering food is still done traditionally, for example food vendors in the cafeteria by way of delivering food orders and bringing food using the hands of food vendors to the buyer's table. Food delivery is traditionally considered ineffective as food vendors have to walk back and forth to deliver food and leave other jobs. For that we need to designed a system of food delivery robot useful for the seller to help deliver food, The prototype design of food delivery robot using Arduino Mega microcontroller, the robot has a place to put food, and able to walk with the DC motor on the wheel. For movement of the robot body direction using a single servo motor and ethernet shield and TP-Link as a communication bridge between Web Browser with Arduino Mega. Web Browser has a function as a user interface that can be used by food vendors to control the robot. The existence of prototype food delivery robot is expected to help the activities of delivering food made by food vendors well so that food vendors can do other more mainstream jobs.
\end{abstract}

Keywords: Food Seller, Arduino Mega, DC Motor, Servo Motor, Web Browser

\begin{abstract}
ABSTRAK
Pada umumnya proses mengantarkan makanan masih dilakukan secara tradisional, contohnya penjual makanan pada kantin dengan cara berjalan kaki mengantarkan pesanan makanan dan membawa makanan menggunakan tangan penjual makanan ke meja saji pembeli. Mengantar makanan secara tradisional dirasa kurang efektif mengingat penjual makanan harus berjalan bolakbalik mengantarkan makanan dan meninggalkan pekerjaan lainnya. Untuk itu perlu dirancang suatu sistem robot pengantar makanan yang berguna bagi penjual untuk membantu mengantarkan makanan, Rancangan prototipe robot pengantar makanan menggunakan mikrokontroler Arduino Mega, robot memiliki tempat untuk meletakkan makanan, serta mampu berjalan dengan adanya motor DC pada roda. Untuk pergerakan arah badan robot menggunakan satu buah motor servo serta ethernet shield dan TP-Link sebagai jembatan komunikasi antara Web Browser dengan Arduino Mega. Web Browser memiliki fungsi sebagai user interface yang nantinya dapat digunakan oleh penjual makanan untuk mengendalikan robot. Adanya prototipe robot pengantar makanan diharapkan mampu membantu kegiatan mengantarkan makanan yang dilakukan oleh penjual makanan dengan baik sehingga penjual makanan dapat mengerjakan pekerjaan lainnya yang lebih utama.
\end{abstract}

Kata Kunci: Penjual Makanan, Arduino Mega, Motor DC, Motor Servo, Web Browser 


\section{PENDAHULUAN}

Abad ke-21 telah membawa kita ke teknologi baru yang didasarkan pada komunikasi nirkabel (wireless) serta penggunaan robot saat ini sudah mencakup seluruh sendi atau pekerjaan manusia, Teknologi mulai mengubah kehidupan kita dalam setiap aspek, sehingga dibutuhkan pemikiranpemikiran yang inovatif dengan menggunakan peralatan yang ada untuk membantu dan mempermudah pekerjaan manusia di masa datang. begitu pula dengan bidang sistem komputer menuntut automatisasi dalam segala hal yang dapat meringankan pekerjaan manusia dan menjadikan segalanya serba praktis dan ekonomis

Di Indonesia pada umumnya proses mengantarkan makanan masih dilakukan secara manual contohnya penjual makanan pada kantin yaitu dengan cara berjalan kaki mengantarkan makanan dan membawa makanan menggunakan tangan penjual makanan ke meja saji pembeli, berbeda dengan Negara maju seperti Amerika, Jepang dan China yang telah menciptakan robot-robot canggih dengan berbagai fungsi yang berguna untuk membantu pekerjaan atau aktifitas mengantar makanan.

Berlatar pada kantin dimana saat ini sistem pengantar makanan kepada pembeli umumnya masih sangat bergantung pada penjual makanan, untuk mengantarkan makanan yang sifatnya masih manual yaitu dengan cara berjalan kaki mengantarkan makanan langsung ke meja saji pembeli dengan menggunakan tangan penjual makanan, hal ini dirasa kurang efektif mengingat penjual makanan harus berjalan bolak-balik mengantarkan makanan.

Berdasarkan beberapa alasan diatas tersebut, maka peneliti mencoba membuat dan merancang sebuah robot pengantar makanan yang dapat membantu penjual makanan mengantarkan makanan, robot yang dirancang memiliki tempat yang berguna untuk meletakkan makanan dan memiliki user interface berupa web browser yang berguna untuk mengendalikan robot, komunikasi antara web browser dengan robot menggunakan Ethernet Shield dan TP-Link yang berguna untuk menghubungkan Arduino Mega dengan jaringan internet sehingga dapat dikendalikan secara jarak jauh, motor dc digunakan untuk menggerakan roda agar robot bisa berjalan serta motor servo berfungsi untuk melakukan pergerakan arah badan robot dan arduino mega sebagai mikrokontrolernya.

\section{PERMASALAHAN}

Permasalahan yang dihadapi oleh penjual makanan adalah dalam hal mengantar makanan yang sifatnya masih dilakukan secara manual, yaitu dengan cara berjalan kaki mengantarkan makanan langsung ke meja saji pembeli dengan menggunakan tangan penjual makanan, sehingga dirasa kurang efektif.

Rumusan masalah dalam penelitian ini adalah bagaimana robot berbasis arduino mega bekerja mengantar makanan dan bagaimana merancang user interface pengendalian robot pengantar makanan pada web browser yang dapat terhubung dengan arduino mega serta apakah prototipe yang akan dibuat dapat membantu penjual makanan mengantarkan makanan

Berdasarkan dari rumusan masalah yang telah dikemuka-kan maka tujuan yang ingin dihasilkan adalah robot pengantar makanan dapat bekerja dengan cara dikontrol melalui jaringan lokal dengan memanfaatkan protokol TCP/IP dan web browser menjadi user interface kontrol robot yang nantinya dapat dikendalikan oleh penjual makanan, komunikasi antar web browser dengan arduino mega menggunakan Ethernet Shield dan TP-Link serta prototipe yang dirancang dapat membantu penjual makanan mengantarkan makanan, karena dengan adanya sistem ini penjual makanan tidak perlu lagi bolak-balik mengantarkan makanan.

\section{METODE PENELITIAN}

Metode pengembangan sistem yang digunakan oleh penulis adalah model prototype jenis I. Prototype memberikan ide bagi pembuat maupun pemakai potensial tentang cara sistem akan berfungsi dalam 
bentuk lengkapnya. Adapun langkah-langkah pada model prototype jenis I sebagaimana yang dikemukakan oleh Raymond McLeod Jr. [6] adalah sebagai berikut :

\section{Mengidentifikasikan kebutuhan pemakai.}

Analis sistem mewawancarai pemakai untuk mendapatkan gagasan dari apa yang diinginkan pemakai terhadap sistem.

\section{Mengembangkan prototype.}

Analis sistem mungkin bekerjasama dengan spesialis informasi lain, menggunakan satu atau lebih peralatan prototype untuk mengembangkan sebuah prototype.

\section{Menentukan apakah prototype dapat diterima.}

Analis mendidik pemakai dalam penggunaan prototype dan memberikan kesempatan kepada pemakai untuk membiasakan diri dengan sistem, tahap pengujian.

\section{Menggunakan prototype.}

Prototype ini menjadi sistem yang dapat dioperasionalkan, tahap implementasi sistem.

\section{LITERATURE REVIEW}

Berikut ini adalah penelitian yang telah dilakukan dalam bentuk tugas akhir dan jurnal ilmiah serta memiliki konsep yang searah dengan penelitian yang akan dibahas dalam penelitian ini, diantaranya yaitu:

1. Penelitian yang telah dilakukan oleh Muhamad Gunawan (2016) dari STMIK RAHARJA sebagai bentuk skripsi dengan judul "Sistem Pesan Makanan Via Bluetooth Dengan Interface Android Berbasis Arduino Uno”. Pada skripsi ini peneliti bertujuan Membuat mekanisme pengontrolan robot yang dapat bekerja dengan secara baik yang mampu mengantarkan makanan dari satu tempat ke tempat lain, yang terhubung via Bluetooth dan dikendalikan dengan aplikasi smartphone android.[3]

2. Penelitian yang telah dilakukan oleh Dian Agus Prayitno (2015) dari Universitas Jember sebagai bentuk skripsi dengan judul "Rancang Bangun Robot Pengantar Makanan Line Tracer Berbasis Mikrokontroler Atmega16”. Pada penelitian ini membahas sistem dari robot pengantar makanan itu sendiri meliputi rangkaian elektronik robot, berjalan menggunakan line tracer dengan mikrokontroler atmega 16, teknik kontrol motor servo dan pemograman robot pengantar makanan dengan CVAVR.[7]

3. Penelitian ini dilakukan oleh M. Febri Rahmansyah (2014) dari Universitas Sumatera Utara Medan, Pada Laporan Skripsi yang berjudul "Prototipe Robot Line Follower Pengantar Berbasis Mikrokontroler Atmega32 Menggunakan Algoritma Fuzzy". Penelitian ini membahas tentang robot pengantar makanan yang memiliki kemampuan untuk mengantarkan makanan dari home base menuju ke meja pesanan secara otomatis yang diimplementasikan meggunakan algoritma fuzzy.[10]

4. Penelitian ini dilakukan oleh Endrowednes Kuantama dkk (2014) dari Universitas Pelita Harapan (UPH), Pada ARPN Journal of Engineering and Applied Sciences, ISSN: 1819-6608 yang berjudul "Simple Delivery Robot System Based On Line Mapping Method". Fokus dari penelitian ini adalah sistem pemetaan robot menggunakan pemetaan line, sistem remote khusus menggunakan frekuensi radio, sistem pengiriman pesan menggunakan lcd dan sistem darurat menggunakan video yang kamera dan remote control. kecepatan maksimum robot adalah $1,045 \mathrm{~m} / \mathrm{s}$, dan dapat menampung beban maksimum 3,5 kg.[5] 
5. Penelitian ini dilakukan oleh M. Z. A Rashid dkk (2013) dari Universiti Teknikal Malaysia Melaka, Pada International Journal of u- and e- Service, Science and Technology (IJUNESST), ISSN: 2005-4246 yang berjudul "Control of Automatic Food Drive-Through System using Programmable Logic Controller (PLC)". pada penelitian ini membahas tentang kontrol otomatis untuk mengantarkan makanan melalui sistem kontrol Programmable Logic Controller (PLC).[1]

6. Penelitian ini dilakukan oleh M. Dhivya Sankari dan M. Pushpavalli (2014) dari Bannari Amman Institute of Technology, Pada The International Journal Of Science \& Technoledge (The IJST), ISSN: 2321-919X, yang berjudul "Automatic Delivering System in Hospital Using GPS Tehnology and Efficint Fault Management". pada penelitian ini memperkenalkan Teknik multilateration menggunakan Smart Global Positioning System (S-GPS). S-GPS jaringan membuat keluar dari toleransi kesalahan dalam kasus kegagalan Sensor. Sebuah algoritma berdasarkan novel digunakan untuk menemukan lokasi tempat dan karena itu meningkatkan Navigasi Pengiriman barang yang dibutuhkan pasien.[11]

Telah banyak penelitian mengenai robot pengantar yang sudah dilakukan ,namun dirasa masih terdapat kekurangan pada masing-masing penelitian. Tujuan dilakukan penelitian ini adalah untuk menutupi kekurangan-kekurangan yang ada pada penelitian sebelumnya, yaitu kekurangan pengontrolan yang masih dilakukan secara offline.

\section{LANDASAN TEORI}

\section{- Arduino Mega}

Arduino dikatakan sebagai sebuah platform dari physical computing yang bersifat open source. Pertama-tama perlu dipahami bahwa kata "platform" di sini adalah sebuah pilihan kata yang tepat. Arduino tidak hanya sekedar sebuah alat pengembangan, tetapi ia adalah kombinasi dari hardware, bahasa pemrograman dan Integrated Development Environment (IDE) yang canggih. IDE adalah sebuah software yang sangat berperan untuk menulis program, meng-compile menjadi kode biner dan meng-upload ke dalam memory microcontroller.

Menurut Feri Djuandi (2011:8) "Komponen utama didalam papan Arduino adalah sebuah mikrokontroler 8 bit dengan merk ATmega yang dibuat oleh Atmel Corporation. Berbagai papan Arduino menggunakan tipe ATmega yang berbeda-beda tergantung dari spesifikasinya, sebagai contoh Arduino Mega 2560 menggunakan ATmega2560.”[2]

\section{- Motor DC}

Menurut Putra (2014:13), "Motor arus searah (Motor DC) ialah suatu mesin yang berfungsi mengubah tenaga listrik arus searah (Listrik DC) menjadi tenaga gerak atau tenaga mekanik, dimana tenaga gerak tersebut berupa putaran dari pada rotor".[8]

\section{- Motor Servo}

Motor Servo adalah sebuah Motor DC yang dilengkapi rangkaian kendali dengan sistem closed feedback yang terintegrasi dalam Motor tersebut. Pada Motor Servo posisi putaran sumbu (axis) dari Motor akan diinformasikan kembali ke rangkaian kontrol yang ada di dalam Motor Servo.[12]

\section{- Web Browser}

Menurut Hastanti dalam jurnal (IJCSS) Indonesian Jurnal on Computer ScienceSpeed (2013) "Web Browser adalah sebuah perangkat lunak atau software yang berfungsi 
untuk menampilkan dan melakukan interaksi dengan dokumen-dokumen yang disediakan oleh server web. Dengan web browser kita dapat memperoleh informasi yang disediakan oleh server web. Web Browser di kenal juga dengan istilah browser, atau peselancar, atau Internet browser adalah suatu program komputer yang menyediakan fasilitas untuk membaca halaman web di suatu komputer.”[4]

\section{PEMBAHASAN}

Tujuan penelitian ini adalah untuk merancang dan membuat sebuah prototype robot pengantar makanan berbasis arduino mega dengan interface web browser sebagai pengendaliannya. Agar mudah dipahami maka penulis membuat diagram blok dan alur kerjanya:

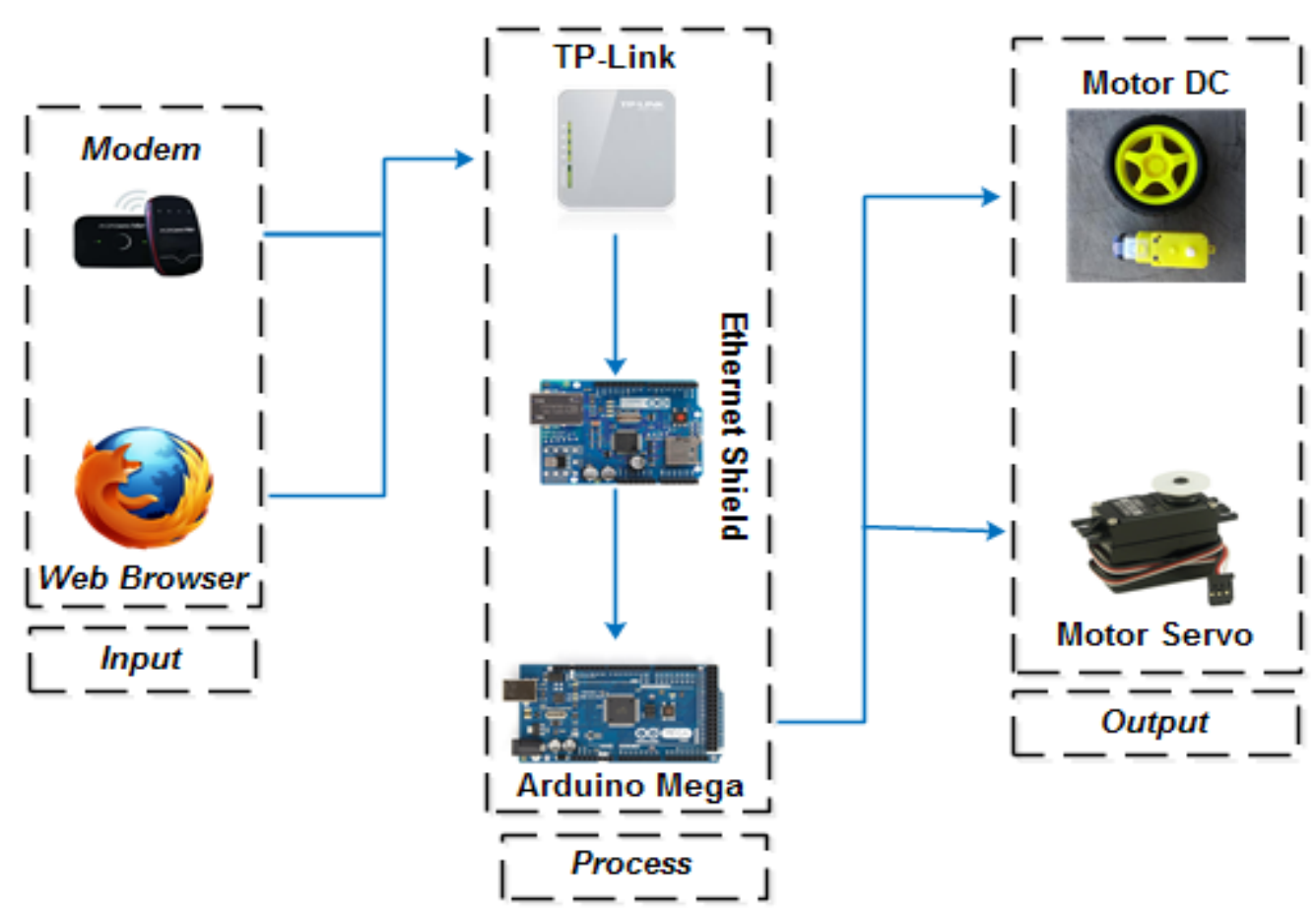

\section{Gambar 1. Diagram Blok Sistem Robot Pengantar Makanan}

Berdasarkan pada gambar diatas, web browser sebagai media input dan juga user interface dari pengontrolan robot yang nantinya dapat dikendalikan oleh penjual makanan dan modem digunakan oleh tp-link untuk mendapatkan ip address. data input berupa informasi yang diberikan oleh web browser akan dihubungkan melalui ethernet shield dan tp-link menuju arduino mega agar dapat diproses, arduino mega menerima informasi sinyal analog yang diubah menjadi sinyal digital berupa kode ASCII (American Standard Code for Information Interchange) yaitu kode standar internasional untuk pertukaran informasi dalam kode huruf dan simbol, Setiap perintah mempunyai masing-masing kode tersendiri. Setelah diolah menjadi data, arduino mega akan mengambil keputusan untuk bertindak. Setelah terjadi input dan proses, maka output sudah dapat dihasilkan. Yaitu, motor dc pada robot berfungsi untuk melakukan pergerakan arah gearbox roda agar robot bisa berjalan, motor servo berfungsi untuk melakukan pergerakan arah badan robot ke kiri dan ke kanan. 


\section{Flowchart Sistem}

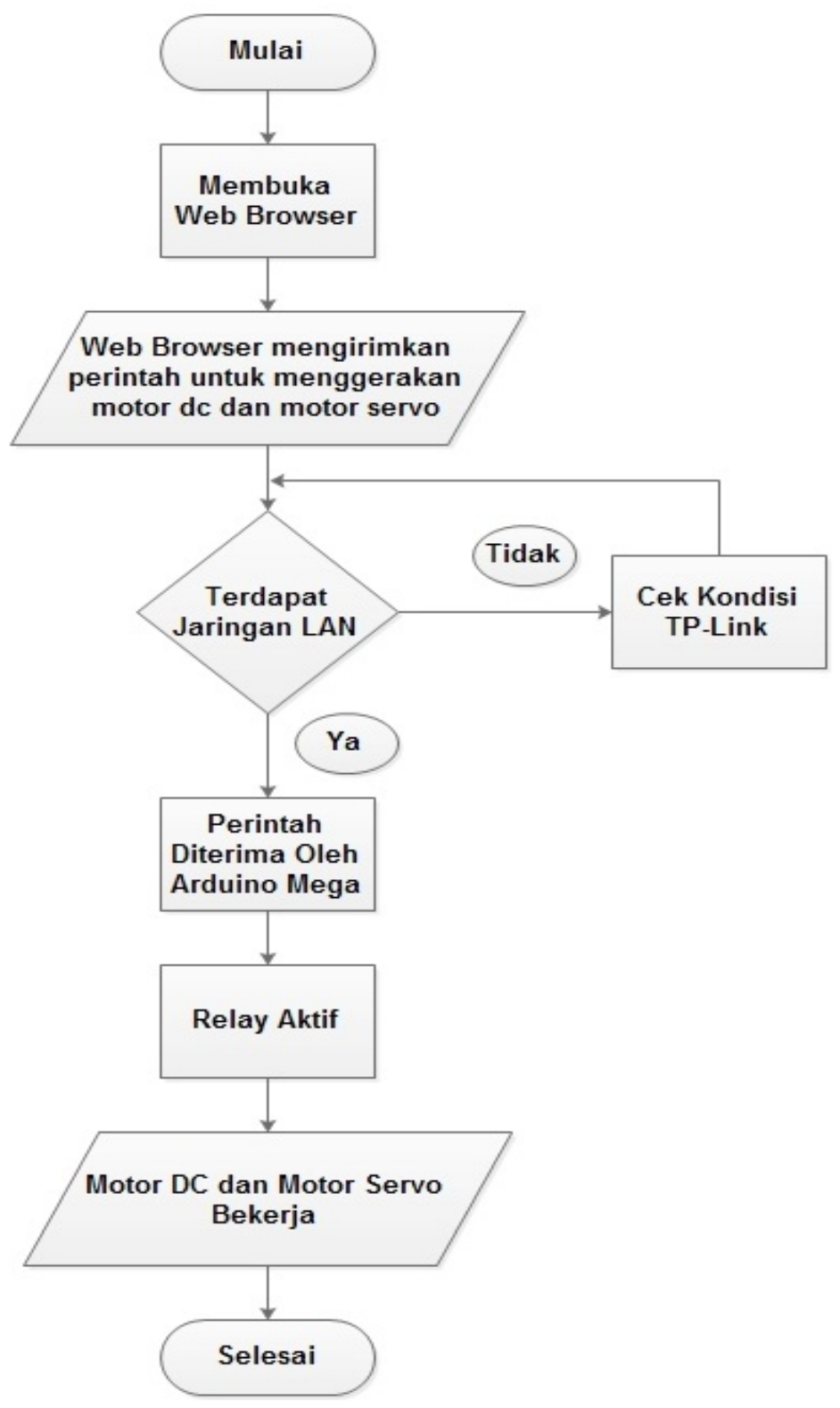

Gambar 2. Flowchart Sistem

Pertama-tama arduino mega harus dikoneksikan ke internet dengan menggunakan ethernet shield dan tp-link untuk mendapatkan alamat ip address. Setelah terkoneksi pada internet, langkah berikutnya adalah membuka web browser, pada web browser nantinya kita akan memasukkan alamat ip address robot tersebut yang akan menampilkan visualisasi beberapa tombol yang berfungsi untuk mengendalikan pergerakan arah robot, ketika tombol ditekan maka informasi berupa data akan diolah arduino mega sebagai perintah untuk menggerakan motor dc dan motor servo.

\section{Rancangan Prototype}

Bentuk perancangan fisik robot pengantar makanan berasal dari material akrilik dan plastik. Di dalam rancangan ini terdapat keseluruhan rangkaian elektronika dan perangkat keras (hardware) yang disusun sesuai fungsi dan kesesuaian rangkaian yang satu dengan yang lainnya agar terlihat rapih. 


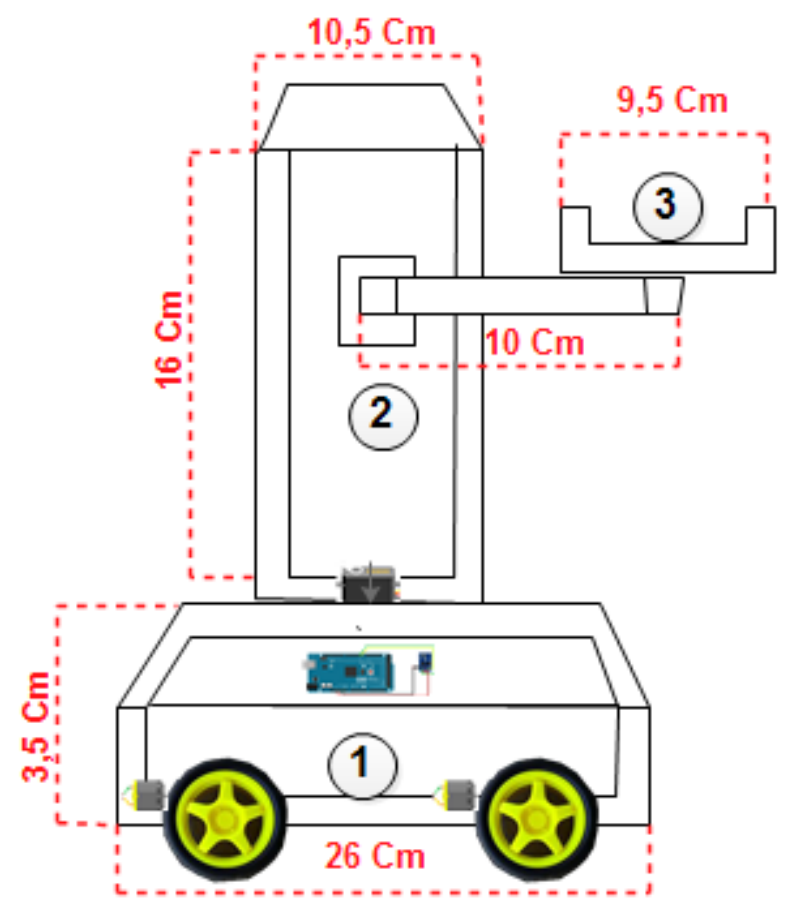

Gambar 3. Rancangan Prototype

Agar lebih mudah dalam memahami rancangan gambar diatas dan keterangannya, dapat dilihat pada tabel 1. Keterangan Desain Prototype.

Tabel 1. Keterangan Desain Prototype

\begin{tabular}{|c|l|l|}
\hline No & \multicolumn{1}{|c|}{ Nama } & \multicolumn{1}{c|}{ Keterangan } \\
\hline 1 & Chassis Robot 4WD & $\begin{array}{l}\text { Terbuat dari bahan akrilik serta didalamnya tedapat } \\
\text { rangkain arduino mega yang tersambung dengan } \\
\text { ethernet shield dan tp-link, serta terdapat rangkaian } \\
\text { motor dc yang berguna untuk menjalankan roda. }\end{array}$ \\
\hline 2 & Badan Robot & $\begin{array}{l}\text { Terdiri dari motor servo didalamnya yang berfungsi } \\
\text { untuk melakukan pergerakan arah badan robot ke kiri } \\
\text { dan ke kanan. }\end{array}$ \\
\hline 3 & Tempat Makanan & Berguna untuk meletakkan makanan. \\
\hline
\end{tabular}

\section{Rancangan Interface Web Browser}

Robot ini dikendalikan secara langsung melalui koneksi nirkabel (wireless) dengan interface sebuah web browser. Tampilan web page sebagai kendali robot ini dirancang sesederhana mungkin agar pengguna mudah untuk mengoperasikanya. 


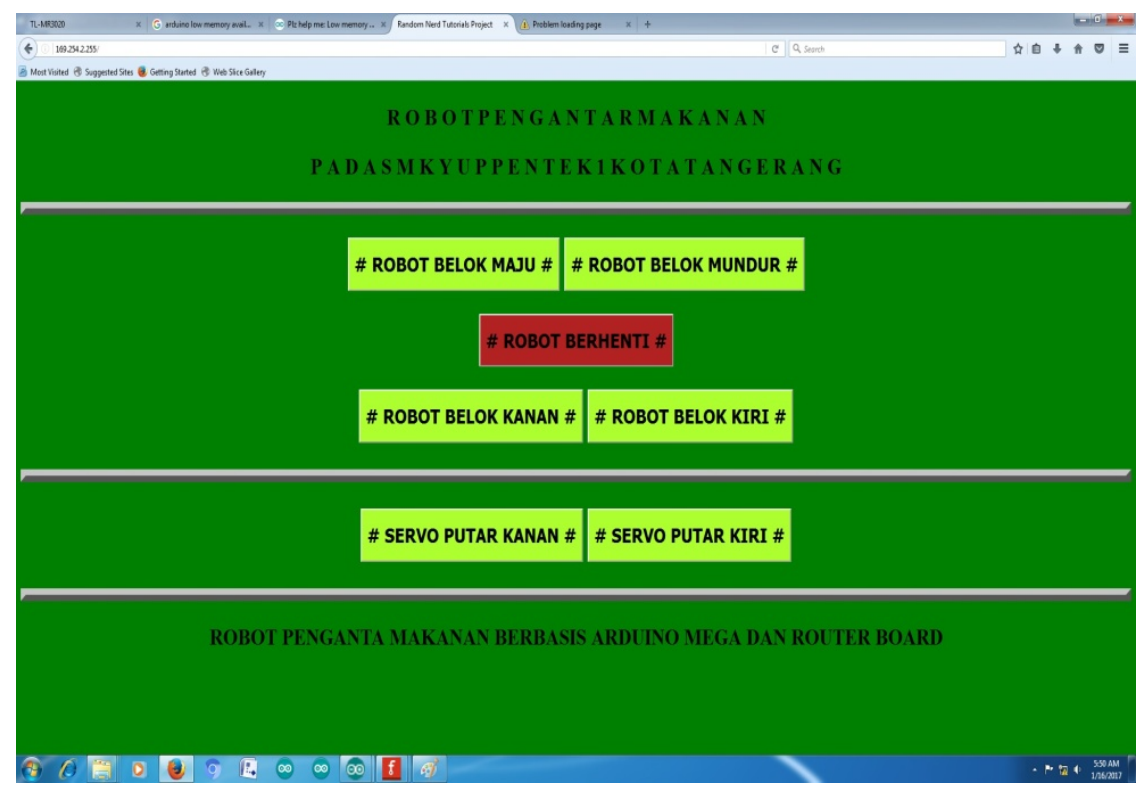

Gambar 4. Rancangan Interface Web Browser

Keterangan dari setiap fungsi masing-masing nomor dalam perancangan web interface adalah sebagai berikut:

Tabel 2. Keterangan Web Interface

\begin{tabular}{|c|l|l|}
\hline No & \multicolumn{1}{|c|}{ Nama } & \multicolumn{1}{c|}{ Keterangan } \\
\hline 1 & $\begin{array}{l}\text { Tombol Pengendali } \\
\text { Motor DC (Roda) }\end{array}$ & $\begin{array}{l}\text { Rangkaian Tombol ini berguna untuk mengendalikan } \\
\text { laju pergerakan arah robot agar dapat berjalan. }\end{array}$ \\
\hline 2 & $\begin{array}{l}\text { Tombol Pengendali } \\
\text { Motor Servo }\end{array}$ & $\begin{array}{l}\text { Rangkaian Tombol ini berguna untuk mengendalikan } \\
\text { badan robot agar dapat bergerak ke kiri dan ke kanan. }\end{array}$ \\
\hline
\end{tabular}

\section{Penulisan Program Pada Arduino Mega}

Untuk memasukkan program ke dalam mikrokontoler ATmega2560, dibutuhkan Driver USB, IDE Arduino 1.6. dan Arduino Mega Board agar program yang dibuat dapat berjalan di dalam mikrokontroler. Instalasi driver untuk Arduino Mega menggunakan Windows 7: hubungkan board dan tunggu windows untuk memulai proses instalasi driver. Pada bagian Ports (COM \& LPT) akan tampak sebuah port terbuka dengan nama Arduino Mega (COMxx), selanjutnya Update Driver Software dan ambil file driver Mega (ArduinoMega.inf). Kemudian masukkan program kedalam mikrokontroler melalui menu Upload seperti pada gambar 5. 


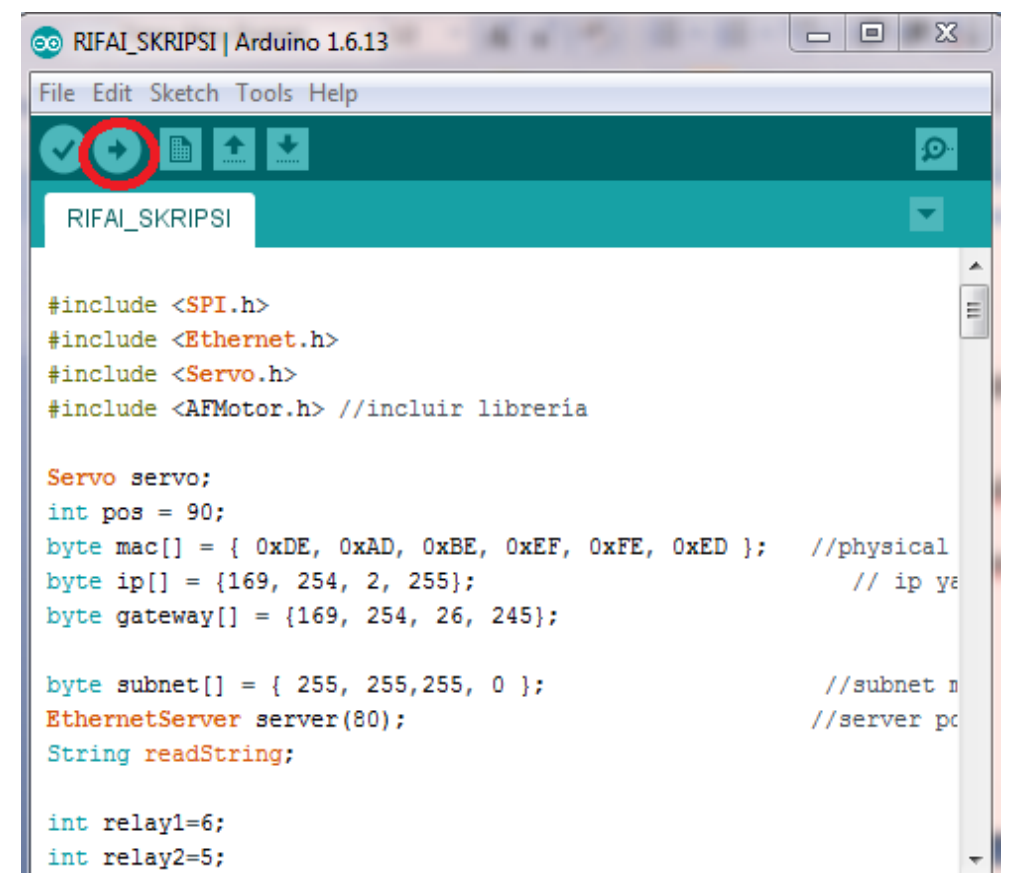

Gambar 5. Upload Program

\section{UJI COBA DAN IMPLEMENTASI}

\section{Uji Coba}

Setelah melakukan berbagai tahapan perancangan, selanjutnya adalah melakukan uji coba pada rangkaian alat yang bertujuan untuk mendapatkan hasil sesuai rancangan. Tujuan dari pengujian ini untuk memastikan seberapa jauh jarak maksimal komunikasi/koneksi antara web browser dengan robot menggunakan ethernet shield melalui tp-link serta hotspot wifi smartfren sebagai akses pointnya, Hasil pengujian dilakukan menggunakan metode black box, dapat dilihat pada tabel 3.

Tabel 3. Pengujian Jarak Maksimal Koneksi Tp-Link MR3020 Pada Area Terbuka

\begin{tabular}{|c|c|c|}
\hline No & Jarak (m) & Keterangan \\
\hline 1 & 1 & Terhubung \\
\hline 2 & 2 & Terhubung \\
\hline 3 & 3 & Terhubung \\
\hline 4 & 4 & Terhubung \\
\hline 5 & 5 & Terhubung \\
\hline 6 & 6 & Terhubung \\
\hline 7 & 7 & Terhubung \\
\hline 8 & 8 & Terhubung \\
\hline 9 & 9 & Terputus \\
\hline 10 & 10 & Terputus \\
\hline
\end{tabular}


Dari percobaan pengujian jarak maksimal koneksi Tp-Link MR3020 dapat dilihat pada Tabel 3. Didapat jarak maksimal jangkauan Tp-Link MR3020 sejauh \pm 8 meter dengan persentase keberhasilan sebesar $100 \%$.

\section{Implementasi}

Setelah melakukan uji coba alat, selanjutnya adalah implementasi sistem. Kebutuhan aplikasi dan robot untuk sistem yang akan diimplementasikan adalah sebagai berikut:

1) Kebutuhan aplikasi

- 1 buah laptop/gadget yang memiliki web browser didalamnya.

2) Kebutuhan robot

- Arduino Mega R3 : sebagai Platform untuk memasukkan program dan mengolah data pada mikrokontroler ATmega 2560.

- Arduino Ethernet Shield W5100 dan Tp-Link MR3020 : Sebagai Gateway penghubung antara Arduino Mega R3 dengan Web Browser.

- Modem Smartfren : Sebagai akses point.

- Motor Servo standar : 1 buah untuk menggerakan pergerakan badan robot, berada pada pin 5.

- Motor DC (gearbox roda) : 4 buah untuk menggerakan pergerakan roda robot, berada pada pin 6, 7, 10, 11.

- Power Supply : sebagai catu daya untuk memberikan tegangan pada alat.

Rancangan Interface Web Browser memiliki beberapa fungsi :

1) Mengontrol robot dengan menekan tombol pada halaman web page.

\section{KESIMPULAN}

Setelah dilakukan perancangan, pembuatan, pengujian dan implementasi yang dilakukan dalam penelitian ini maka dapat dikemukakan beberapa kesimpulan sebagai berikut:

Protoype robot pengantar makanan berbasis arduino mega dapat bekerja dengan cara dikontrol melalui jaringan lokal dengan memanfaatkan protokol TCP/IP. Robot terlebih dahulu dikoneksikan ke jaringan wifi lokal menggunakan Ethernet Shield dan TP-Link agar siap untuk dikontrol melalui iPad, Laptop/PC, Smartpone yang terkoneksi pada jaringan yang sama serta memiliki aplikasi web browser. Dengan pembuatan aplikasi berbasis web, robot ini dapat dikendalikan melalui semua perangkat yang memiliki web browser serta prototipe yang dirancang diharapkan mampu membantu penjual makanan mengantarkan makanan, karena dengan adanya sistem ini penjual makanan tidak perlu lagi bolak-balik mengantarkan makanan.

\section{DAFTAR PUSTAKA}

1. A Rashid, M. Z. dkk. 2013. "Control of Automatic Food Drive-Through System using Programmable Logic Controller (PLC)". Melaka: International Journal of u- and e-Service, Science and Technology (IJUNESST), ISSN: 2005-4246. 
2. Feri Djuandi. 2011. “Pengenalan Arduino”.E-book. www.tobuku.com, Juli 2011.

3. Gunawan, Muhammad. 2016. "Sistem Pesan Makanan Via Bluetooth Dengan Interface Android Berbasis Arduino Uno”. Skripsi. Tangerang: STMIK Raharja.

4. Hastanti. Rulia Puji, Wardati. Indah Uly, Purnama. Bambang Eka. 2013. "Sistem Penjualan Berbasis Web (E-Commerce) Pada Tata Distro Kabupaten”. Surakarta: IJCSS - Indonesian Jurnal on Computer Science - Speed - FTI UNSA

5. Kuantama, Endrowednes. Lewis Lukas, Albert Brian. Mardjoko, Pono Budi. 2014. "Simple Delivery Robot System Based On Line Mapping Method". Tangerang: ARPN Journal of Engineering and Applied Sciences Vol. 9, No.11 November 2014.

6. McLeod Jr., Raymond, 2001, Sistem Informasi Manajemen, Edisi Ketujuh, PT Prenhallindo, Jakarta.

7. Prayitno, Dian Agus. 2015. "Rancang Bangun Robot Pengantar Makanan Line Tracer Berbasis Miktokontoler Atmega16”. Tugas Akhir. Jember: Universitas Jember.

8. Putra, Dimas Harind Yudha, Riswan Dinzi. 2014. "Studi Pengaturan Kecepatan Motor Dc Shunt Dengan Metode Ward Leonard”. Sumatera: Universitas Sumatera Utara (USU).

9. Rahmansyah, M. Febri. 2014. Prototipe Robot Line Follower Pengantar Makanan Bebasis Mikrokontroler Atmega32 Menggunakan Algoritma Fuzzy. Skripsi. Meda: Universitas Sumatera Utara.

10. Sankari, M. Dhivya dan Pushpavalli , M. 2014. “Automatic Delivering System in Hospital Using GPS Tehnology and Efficint Fault Management”. India: The International Journal Of Science \& Technoledge (Theijst), ISSN: 2321 - 919X.

11. http://elektronika-dasar.web.id (diakses pada tanggal 05-01-2017) 